
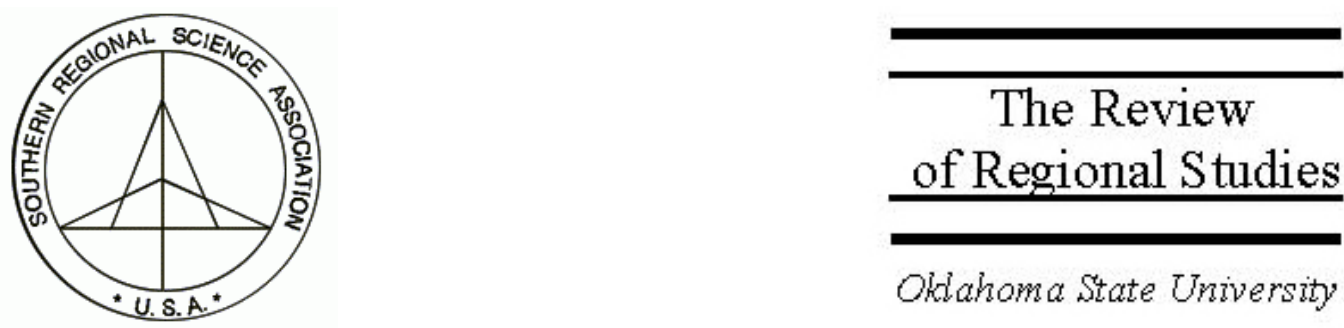

Oklahoma State University

\title{
On the Nature of Regional Price Differentials: Some Panel Results for Italy
}

\author{
Carla Massidda \\ Department of Economics, University of Cagliari, Viale S. Ignazio, 17, 09123, Cagliari, \\ Italy,e-mail:massidda@unica.it \\ Paolo Mattana \\ Department of Economics, University of Cagliari, Viale S. Ignazio, 17, 09123, Cagliari, \\ Italy,e-mail: mattana@unica.it
}

\begin{abstract}
We combine panel data with SVECM methodologies to assess the role of real shocks in determining price differentials in Italy. The main results can be summarized as follows. At a national level, we find strong evidence of persistent price and productivity misalignments across regions. In accordance with the Balassa-Samuelson Hypothesis, such misalignments are positively correlated in all samples. Aggregate productivity seems to be the driving force at the national level. The adjustment mechanism is rather intricate and changes across the country. The retrieval of the structural coefficients is also rich in powerful insights into the functioning of the Italian economy.
\end{abstract}

Keywords: PPP; Long-run inflation differentials; Panel data; Multivariate cointegration analysis; Structural parameters

\section{JEL classification: C33; E31}

This paper was presented at the Workshop on Mezzogiorno: Sviluppo e Nuove Teorie della Crescita, Capua, 29 April 2005. Thanks are due to Erasmo Papagni, Carlo Altavilla, and two anonymous referees for helpful comments. Financial support from the MIUR and the University of Cagliari is gratefully acknowledged. 


\section{INTRODUCTION}

Recent literature has found that departures from Purchasing Power Parity (PPP) are fairly common in the fixed exchange rate context of EMU countries (cf., inter alia, Ortega 2003). ${ }^{1}$ A frequently quoted explanation for this phenomenon is the BalassaSamuelson Effect (BSE), which, in a common-currency setting with countries at conspicuously different stages of economic development, implies a positive correlation between relative prices and relative growth performance. ${ }^{2}$

Studies on the empirical relevance of the BSE within EMU countries have been mainly conducted at an aggregate-data national level (cf., inter alia, Alberola and Tyrvainen 1998; Égert 2002; Issing 2001; Ortega 2003; Lommatzsch and Tober 2004; Honohan and Lane 2003; Bergin, Glick, and Taylor 2004). ${ }^{3}$ There are, however, good reasons to believe that a more disaggregated regional approach could also be rich in powerful insights. Indeed, as made clear by Beck, Hubrich, and Marcellino (2006), sources of heterogeneous coupling of inflation rates and real factors can be found not only at aggregate common-currency and national levels, but also at a more disaggregate local level. Special idiosyncratic regional factors may be, for example, regional and/or sector-specific wage agreements, heterogeneous degrees of labor market mobility across regions, and regional spillovers, all of which make regional location specifications important. All this turns out to have fundamental implications for the monetary policy stance of the European Central Bank (ECB), which is taking an increasing interest in monitoring the consequences of its one-size-fits-all approach. Naturally, this kind of information is also particularly useful for local policy makers. In this respect, studies on the relevance of the BSE may produce important information on phenomena like regional economic convergence or long-lasting regional productivity disparities, or even on dualism such as that existing between the east and west of Germany or the north and south of Italy. Another reason for preferring the regional environment is that factors that could bias national comparisons, e.g., heterogeneous fiscal regimes, tax levels, regulatory structures, and economic policies, are not relevant in integrated within-borders contexts.

In spite of theoretical interest in the potential of disaggregate-data analyses, investigations of regional links between price misalignments and real factors in Europe are surprisingly scarce. To our knowledge, only Nenna (2001) and Alberola and Marqués (1998, 2001) have produced evidence on the regional relevance of the BSE for EMU countries,

\footnotetext{
${ }^{1}$ The evaluation of the permanence of price differentials among common currency areas allows the analysis to abstract from many factors, such as trade barriers and nominal exchange rate volatility, which bias the rate of convergence of relative prices in multicurrency settings. Cf. BlancoGonzález and Fullerton (2006) for recent evidence on this issue.

${ }^{2}$ The analytics of the BSE are exhaustively expounded in Obstfeld and Rogoff (1996).

${ }^{3} \mathrm{An}$ interesting debate regards also the relevance of the BSE for countries in transition. Cf., inter alia, Drine and Rault (2003), Égert (2002), and Mihalijek and Klau (2004).
} 
namely for Italian and Spanish regions. ${ }^{4}$ What is interesting here is that the cited literature seems to agree in finding evidence of a significant role for real factors. However, whereas Nenna's (2001) results are in line with the theoretical prediction of a positive correlation between relative prices and relative growth performance, Alberola and Marqués's (1998, 2001) are consistent with a more traditional Supply-Demand Mechanism (SDM) and seem to imply that higher growth in one region is associated with a fall in relative prices. ${ }^{5}$

In this paper we aim to contribute to this field. We propose a four-variate Structural Vector Error Correction Model (SVECM) investigation of the long-run and contemporaneous relationships between the levels of regional and national prices and the levels of regional and national productivity indexes for the Italian economy. This environment allows us to abstract from the standard relative-price relative-growth-performance framework typical of the cited literature, where local (nominal or real) shocks are not distinguishable from those originating from the numeraire and where fundamental information on the nature of long-run relationships between prices and productivities is not observable.

From a more technical point of view, our analysis combines a panel dataset with SVECM estimation in an innovative approach that is still being developed in econometric theory. We refer to the recent approach suggested by Larsson, Lyhagen, and Löthgren (2001). This approach extends Johansen's maximum likelihood methodology (Johansen 1988, 1991, 1995) into a panel data setting. It allows testing for cointegration in heterogeneous panel data models with a great deal of flexibility. This estimation approach is particularly useful when the long-run is given by conditions expected to be homogeneous across units while the short-run adjustment depends on the specific characteristics of the unit. This strongly enhances the efficiency of the estimation and at the same time returns consistent estimation of the mean of short-run coefficients across units. In the expectation that heterogeneity will emerge across the country, our contribution deals with information arising from the entire sample and from two sub-samples clustering Northern and Central-Southern regions. ${ }^{6}$

The rest of this paper is organized as follows. Section 2 describes the SVECM specification and provides some hints on the technicalities attached to our methodology. Section 3 illustrates the estimation technique. Section 4 discusses the results. A final section reassesses the main findings of the paper.

\footnotetext{
${ }^{4}$ Recent non-concluding applications on regional price convergence for other economically integrated areas include Parsley and Wei (1996) and Engel and Rogers (1996) for both the U.S. and Canada; Cecchetti, Mark, and Sonora $(1998,2002)$ for the U.S.; Ceglowski (2003) for Canada; Das and Bhattacharya (2005) for India; and Fan and Wei (2006) for China.

${ }^{5}$ The opposite-in-sign response to a real shock in the two theoretical settings is justified by different underlying assumptions on wage determination: national wage links in the SDM and sectoral wage links under the BSE.

${ }^{6}$ Details on macro-area composition are in the Appendix.
} 


\section{A STRUCTURAL VECTOR ERROR CORRECTION MODEL}

To conduct our empirical analysis, we consider a finite-order VAR of the form

$$
X_{i, t}=\sum_{k=1}^{m} A_{i, k} X_{i, t-k}+e_{i, t}
$$

where $m$ is the appropriate order of lag polynomial; $A_{i, k}$ are matrices containing the parameters of interest for the $i$ th region; and $e_{i, t}$ the error term is a $(4 \times 1)$ vector of observable residuals, again generated from estimation in the $i$ th region. In the above model $X_{i, t}=\left[Y_{n, t}, Y_{i, t}, P_{n, t}, P_{i, t}\right]^{\prime}$ is a vector containing the variables of interest. In particular, $Y_{n, t}$ and $Y_{i, t}$ are national and region $i(\log )$ per-capita GDPs at time $t$, while $P_{n, t}$ and $P_{i, t}$ are national and region $i(\log )$ price levels at time $t$.

Before starting the analysis, there is the need for preliminary study of the dynamic properties of the data by means of unit root tests. In this respect, it has been widely acknowledged that standard univariate unit root tests can have low power. However, recently developed panel unit root tests that rely on a broader information set can be used to gain power and to provide more reliable evidence. In this paper, the LLC (Levin, Lin, and Chu 2002), the IPS (Im, Pesaran, and Shin 2003), and the HD (Hadri 2000) tests are applied. These testing procedures allow for deterministic and dynamic effects differing across the panel members. The first two are generalizations of the ADF principle. The null of a unit root is tested against the alternative of a stationary process for all (LLC) or at least for one (IPS) cross section. The hypotheses are interchanged by the HD procedure, which adapts the KPSS test to panels.

When the outcome of the investigation suggests that the variables are non-stationary and integrated to the same order, the likely misinterpretation of the long-run relationship among the variables that results from forcing them to be stationary through differentiation is avoided by taking into account the cointegration properties of the variables. Therefore, without imposing constraints on the direction and magnitude of the response to a shock, the relationships among the variables can be rewritten with the following VECM representation by subtracting $X_{i, t-1}$ from both sides of equation (1)

$$
\Delta X_{i, t}=\alpha_{i} \beta_{i}^{\prime} X_{i, t-1}+\sum_{k=1}^{m} \Gamma_{i, k} \Delta X_{i, t-k}+e_{i, t},
$$

where $\Gamma_{i, k}$ contains the coefficients of the variables in differences (with $k$ indicating the lag order, with a maximum lag of $m), \beta_{i}^{\prime}$ is region $i$ th $\left(4 \times r_{i}\right)$ matrix of long-run coefficients with $r_{i}$ the cointegration rank of the system. The motivation for this model is clearly established in the literature. If $\beta_{i}^{\prime} X_{i, t-1}=c$ represents the underlying economic relations among variables with $\beta_{i}^{\prime}$ matrix of long-run coefficients, $\alpha_{i}$ becomes the matrix of adjustment coefficients of the $i$ th region, through which agents react to disequilibrium errors $\beta_{i}^{\prime} X_{i, t-1}=c$ in order to bring back the variables to their equilibrium level. The 
absolute value of the $\alpha_{i}$ coefficients can be used to obtain information on the time span needed to restore the long-term equilibrium. In particular, to obtain the number of periods necessary for the system to close 50 percent of a disequilibrium (half-lives), the formula $(1-\alpha)^{\tau}=(1-0.5)$ can be used. The closer the parameter is to unity, the faster the adjustment. When, in the short-run equation for a specific variable, the adjustment coefficient of the $r$ th cointegrating relation happens to be zero, the variable is not adjusting to that disequilibrium error.

\subsection{Identifying the Cointegrating Space}

We have three possible outcomes relating to the dimension of the $\alpha_{i} \beta_{i}^{\prime}$ impact matrix. The least interesting cases are where the rank is zero or full. In these cases, either the variables are stationary or are not cointegrated. But when the impact matrix is estimated to be of intermediate rank $r$, there exist $r$ cointegrating vectors, i.e., linear combinations linking the variables in the long-run. Since these vectors are not uniquely determined in terms of stationarity, it is necessary to impose some restrictions in order to identify the cointegrating space. ${ }^{7}$ This requires one normalization and $(r-1)$ restrictions on each cointegrating vector.

In order to provide a clear picture of the identification procedure, we find it convenient to anticipate the $r=3$ case found below in our empirical investigation. When $r=3$, the four-variable case implies that the variables are cointegrated in groups of two. For the vectors to have an economic meaning, we impose the following structure to the matrix of long-run elasticities

$$
\left[\begin{array}{ccc}
0 & \beta_{2 i} & \beta_{3 i} \\
0 & 1 & 0 \\
\beta_{1 i} & 0 & 1 \\
1 & 0 & 0
\end{array}\right]
$$

such that the three cointegration relationships become

$$
\begin{aligned}
& P_{i, t}+\beta_{1 i} \times P_{n, t}, \\
& Y_{i, t}+\beta_{2 i} \times Y_{n, t}, \\
& P_{n, t}+\beta_{3 i} \times Y_{n, t} .
\end{aligned}
$$

\footnotetext{
${ }^{7}$ As a matter of facts, the estimation of the ECM merely returns the ML estimates of the unrestricted cointegrating relations and is useless in terms of economic interpretation.
} 
These equations describe the long-run relationships between the four variables of the system. $\beta_{1 i}$ represents region $i$ th elasticity cointegrating local and national prices. It can be used to establish whether relative prices are constant or are increasing/decreasing in region $i$. In more detail, a test for the validity of the (strong version) of the law of one price can be simply conducted by evaluating the restriction $\beta_{1 i}=-1$ in equation (4). Coefficient $\beta_{2 i}$ is region ith elasticity cointegrating local and national productivities. As before, a non-rejection of the restriction $\beta_{2 i}=-1$ would imply constant relative productivity. Finally, the sign and magnitude of the $\beta_{3 i}$ coefficient, cointegrating national price and productivity indexes, would allow us to test for the conventional wisdom that richer countries or regions have higher price levels than poorer ones.

With this identification of the cointegrating space, we are in a position to evaluate the theoretical hypothesis discussed in the introduction by jointly considering coefficients. In particular, if it can be shown that both $\beta_{1 i}$ and $\beta_{2 i}$ are, in modulus, larger (lower) than one, relative prices and relative productivity are increasing (decreasing) in the long run; this implies that the correlation between relative prices and relative growth performance is positive and that the pre-conditions for the BSE prevail. Conversely, if one of the two elasticities is lower than one, relative prices and relative productivities move in opposite directions and the SDM dominates.

\subsection{Identifying Contemporaneous Relationships}

As is sometimes claimed, it is difficult to give an economic interpretation to reducedform VAR equations. ${ }^{8}$ This problem is avoided by using structural vector autoregressions where economic theory or econometric considerations are used to impose a structure on the model. In this class of models, identification focuses on the errors of the system, which in turn are interpreted as linear combinations of exogenous shocks.

The reduced form VECM presented in equation (2) is derived from the following structural dynamic linear model:

$$
A_{i} X_{i, t}=\sum_{j=1}^{k} A_{i, j} X_{i, t-j}+B_{i} \varepsilon_{i, t}
$$

where $\varepsilon_{i, t}$ is a vector of non-observable structural innovations $\sim N\left(0, I_{n}\right)$. Here, the matrix $A_{i}$ allows for the modeling of region $i$ th instantaneous relationship, while $B_{i}$ is a diagonal structural form matrix of parameters, again referring to region $i$. Starting from the $\frac{n(n+1)}{2}$ free elements of $\hat{\Sigma}$, lack of identification emerges from the estimation of the $\left(n^{2}+n^{2}\right)$ elements of $A_{i}$ and $B_{i}$. The identification problem is solved by restricting the contemporaneous relation matrix to a lower triangular form. ${ }^{9}$ We have therefore

\footnotetext{
${ }^{8} \mathrm{Cf}$. Urbain (1992) and Boswijk (1995a, 1995b).

${ }^{9} \mathrm{Cf}$. Amisano and Giannini (1997) for a technical description of the estimation procedure for the so-called $A B$ model.
} 


$$
\left[\begin{array}{llll}
1 & 0 & 0 & 0 \\
a_{21} & 1 & 0 & 0 \\
a_{31} & a_{32} & 1 & 0 \\
a_{41} & a_{42} & a_{43} & 1
\end{array}\right]\left[\begin{array}{l}
e^{Y_{n, t}} \\
e^{Y_{i, t}} \\
e^{P_{n, t}} \\
e^{P_{i, t}}
\end{array}\right]=\left[\begin{array}{llll}
b_{11} & 0 & 0 & 0 \\
0 & b_{22} & 0 & 0 \\
0 & 0 & b_{33} & 0 \\
0 & 0 & 0 & b_{44}
\end{array}\right]\left[\begin{array}{l}
\varepsilon^{Y_{n, t}} \\
\varepsilon_{Y_{i, t}} \\
\varepsilon^{P_{n, t}} \\
\varepsilon^{P_{i, t}}
\end{array}\right],
$$

where $a_{p q}$ and $b_{p q}$ are the $p$ th row and $q$ th column elements of the $A_{i}$ and $B_{i}$ matrices, respectively. This solution imposes a recursive structure on the economy, resulting in a particular causal ordering of the variables in the system whose validity can be confirmed by applying standard Granger Causality tests. According to our specification, we first have $Y_{n, t}=b_{11} \varepsilon^{Y_{n, t}}$. This equation shows that at the aggregate level, productivity is only affected by its own disturbance. According to the restriction structure implied by the form of the matrices $A_{i}$ and $B_{i}$, we also have $Y_{i, t}=-a_{21} Y_{n, t}+b_{22} \varepsilon^{Y_{i, t}}$. This equation shows that productivity at the regional level is simultaneously related to the national level of output and instantaneously affected by locally specific productivity shocks.

Again according to the selected restrictions, prices follow more complicated formation laws. We have that at the national level $P_{n, t}=-a_{31} Y_{n, t}-a_{32} Y_{i, t}+b_{33} \varepsilon^{P_{n, t}}$, whereas $P_{i, t}=-a_{41} Y_{n, t}-a_{42} Y_{i, t}-a_{43} P_{n, t}+b_{44} \varepsilon^{P_{i, t}}$ is valid at the local level. These relationships imply that while the national price index is simultaneously related to both aggregate and local productivity and affected by its own disturbance, the local price index (the less exogenous variable according to the identification scheme) is simultaneously related to all variables and also depends on its own disturbance.

Once the identification scheme is provided, Impulse-Response analysis can be implemented to describe how the system with the four endogenous variables reacts over time to a one-time shock to one of the four structural disturbances.

\section{ESTIMATION TECHNIQUE}

Our sample is characterized by relatively large time series $(T)$ and cross section $(N)$. In such conditions, there are a number of alternative methods for estimating cointegrating VARs that allow for different degrees of parameter heterogeneity across units. At one extreme, we can find the fully heterogeneous coefficient model, which imposes no crossunits parameter restrictions and can be estimated on a unit-by-unit basis. At the other extreme, there is the fully homogeneous-coefficient model (the pooled estimator), which requires complete homogeneity of all slope and intercept coefficients across units.

In between, there is a large number of other estimators. The pooled mean group (PMG) estimator, introduced by Pesaran, Shin, and Smith (1999), restricts the long-run coefficients to be the same across units but allows the short-run coefficients to be crosssection specific. The PMG estimator also generates consistent estimates of the mean of 
short-run coefficients across units by taking the unweighted average of the individual country coefficients. The choice among these estimators faces a general trade-off between consistency and efficiency. Estimators that impose cross-country constraints dominate the heterogeneous estimators in terms of efficiency if the restrictions are valid. If they are false, however, the restricted estimators are inconsistent.

For our purposes, the PMG estimator seems to offer the best available compromise in the balance of consistency and efficiency. This estimator is in fact particularly appropriate when the long-run is given by conditions expected to be homogeneous across units while the short-run is cross-section specific. The estimator in our specific case is implemented by means of the approach recently suggested by Larsson, Lyhagen, and Löthgren (2001) (LLL henceforth). The approach extends Johansen's maximum likelihood estimation (Johansen 1988, 1991, 1995) into a panel data setting. It implies a multistep estimation procedure. First of all, once the appropriate lag length of the VAR is selected, we are required to determine the rank $r$ of the stochastic matrix $\alpha \beta^{\prime}$. This is done by calculating the Johansen trace statistic $L R_{i, T}$ for each unit and then averaging across the $N$ units to obtain the following:

$$
\overline{L R}_{N, T}=\frac{1}{N} \sum_{i=1}^{N} L R_{i, T}
$$

LLL show that panel inference on the rank $r$ can be conducted by comparing

$$
\bar{\Psi}_{L R}=\sqrt{N} \frac{\overline{L R}_{N, T-E\left(Z_{k}\right)}}{\sqrt{\operatorname{Var}\left(Z_{k}\right)}},
$$

where $E\left(Z_{k}\right)$ and $\operatorname{Var}\left(Z_{k}\right)$ are the mean and the variance of the asymptotic trace statistic, tabulated in LLL to critical values from a $N(0,1)$ distribution.

Finally, we need to estimate the parameters of interest separately for each cross section; then individual cross-section information is conveyed into the panel context by calculating the averages of all relevant parameters. This means that long-run parameters and adjustment coefficients must ultimately undergo a homogeneity analysis to check whether each cross-section parameter is equal across the panel. Hypothesis testing of this kind results in LR statistics that are asymptotically distributed $\chi^{2}(1)$. If we assume independence, the sum of the LR individual values is, in turn, distributed as a $\chi^{2}(N \times 1)$. The same mechanism can also be used to investigate the econometric acceptability of the restrictions in connection with economic hypotheses of interest. Again, the restrictions on the parameters are evaluated cross section by cross section and, as before, hypothesis testing results in LR statistics that are asymptotically distributed as $\chi^{2}(q)$ with $q$ number of restrictions. 


\section{EMPIRICAL ANALYSIS}

In this section, we present the results of the application of the LLL estimation procedure to our model. The data refers to 20 Italian regions observed for the period 1980$2004^{10}(N=20, T=25)$. We first study the unit root and cointegration properties of our set of variables. We then present results relating to the full-sample estimation of the reduced-form VECM in equation (2). Finally, the results obtained for the two macroareas, North and Center-South, are discussed. ${ }^{11}$ At this more homogenous level, both the reduced-form VECM estimation and the identification of the structural coefficients are discussed.

\subsection{Unit Root and Cointegration Properties of the Series}

As already discussed in the methodology section, the first step of our analysis consists in studying the order of integration of the variables. The LLC, IPS, and HD tests ${ }^{12}$ for the levels and for the first differences of the variables have been computed for the full sample and for the two macro-areas. All statistics are asymptotically distributed as standard normal with a left side rejection area except for the HD test, which is right sided. All tests with the variables in levels (differences) have been performed assuming the presence of a deterministic time trend (constant). ${ }^{13}$

The results regarding both the full sample and the macro-area level are reported in Table 1. We find evidence supporting the presence of only one unit root in all series. However, sometimes the tests produce conflicting results. In particular, whereas the IPS test is in favor of I(1)-ness for all samples and variables, the LLL test rejects the null of non-stationarity against trend stationarity for the price level for the full sample and for North. ${ }^{14}$ Contradictory results also arise from the HD test, which rejects the null of stationarity for the price level in difference at both the national and macro-area levels. ${ }^{15}$

\footnotetext{
${ }^{10}$ ISTAT provides longer regional time series. The decision to restrict the sample is motivated by the large number of outliers characterizing previous periods. Some observation-specific dummies, however, are still considered in particular cases.

${ }^{11}$ Details on the macro-areas composition are in the Appendix.

${ }^{12}$ The consistent estimator of the long-run residual variance relevant for the LLC and HD statistics is obtained using the Bartlett kernel and the automatic bandwidth parameter suggested by Newey and West.

${ }^{13}$ This decision is based on the individual ADF statistics.

${ }^{14}$ However, the $p$-values never exceed the 1 percent critical value.

${ }^{15}$ The identification of the correct order of the price variables is a well-known problem in the empirical literature, as prices and inflation rates are well described by different orders of integration according to the sample range. In our panel context, this problem can be considered less damaging than in the general case since, as discussed in Karlsson and Löthgren (2000), it might depend on extreme values undertaken by individual tests.
} 
TABLE 1

Panel Unit Root Tests

\begin{tabular}{|c|c|c|c|}
\hline \multirow[b]{2}{*}{ Variable } & \multicolumn{3}{|c|}{ Full Sample } \\
\hline & LLC & IPS & $\mathrm{HD}$ \\
\hline $\bar{P} P_{i, t}$ & $\begin{array}{l}-2.02^{*} \\
(0.02)\end{array}$ & $\begin{array}{l}-0.02 \\
(0.49)\end{array}$ & $\begin{array}{l}12.35^{* *} \\
(0.00)\end{array}$ \\
\hline$Y_{i, t}$ & $\begin{array}{l}-0.30 \\
(0.38)\end{array}$ & $\begin{array}{l}-0.90 \\
(0.18)\end{array}$ & $\begin{array}{l}6.38^{* *} \\
(0.00)\end{array}$ \\
\hline$\Delta P_{i, t}$ & $\begin{array}{l}-8.89^{* *} \\
(0.00)\end{array}$ & $\begin{array}{l}-5.22^{* *} \\
(0.00)\end{array}$ & $\begin{array}{l}12.21^{* *} \\
(0.00)\end{array}$ \\
\hline \multirow[t]{2}{*}{$\Delta Y_{i, t}$} & $\begin{array}{c}-16.02^{* *} \\
(0.00) \\
\end{array}$ & $\begin{array}{c}-15.32^{* *} \\
(0.00) \\
\end{array}$ & $\begin{array}{l}-0.52 \\
(0.70)\end{array}$ \\
\hline & \multicolumn{3}{|c|}{ North } \\
\hline Variable & LLC & IPS & HD \\
\hline$\overline{P_{i, t}}$ & $\begin{array}{l}-2.01^{*} \\
(0.02)\end{array}$ & $\begin{array}{c}0.39 \\
(0.65)\end{array}$ & $\begin{array}{l}7.69^{* *} \\
(0.00)\end{array}$ \\
\hline$Y_{i, t}$ & $\begin{array}{c}0.27 \\
(0.60)\end{array}$ & $\begin{array}{l}-0.07 \\
(0.47)\end{array}$ & $\begin{array}{l}4.73^{* *} \\
(0.00)\end{array}$ \\
\hline$\Delta P_{i, t}$ & $\begin{array}{l}-5.80^{* *} \\
(0.00)\end{array}$ & $\begin{array}{l}-3.52^{* *} \\
(0.00)\end{array}$ & $\begin{array}{l}7.58^{* *} \\
(0.00)\end{array}$ \\
\hline \multirow[t]{2}{*}{$\Delta Y_{i, t}$} & $\begin{array}{l}-8.03^{* *} \\
(0.00)\end{array}$ & $\begin{array}{l}-7.50^{* *} \\
(0.00)\end{array}$ & $\begin{array}{l}-0.21 \\
(0.58) \\
\end{array}$ \\
\hline & \multicolumn{3}{|c|}{ Center-South } \\
\hline Variable & LLC & IPS & HD \\
\hline $\bar{P} P_{i, t}$ & $\begin{array}{l}-1.47 \\
(0.07)\end{array}$ & $\begin{array}{c}0.29 \\
(0.62)\end{array}$ & $\begin{array}{l}5.53^{* *} \\
(0.00)\end{array}$ \\
\hline$Y_{i, t}$ & $\begin{array}{l}-0.25 \\
(0.40)\end{array}$ & $\begin{array}{l}-0.73 \\
(0.23)\end{array}$ & $\begin{array}{l}2.87^{* *} \\
(0.00)\end{array}$ \\
\hline$\Delta P_{i, t}$ & $\begin{array}{l}-4.65^{* *} \\
(0.00)\end{array}$ & $\begin{array}{l}-2.90^{* *} \\
(0.00)\end{array}$ & $\begin{array}{l}5.35^{* *} \\
(0.00)\end{array}$ \\
\hline$\Delta Y_{i, t}$ & $\begin{array}{l}-6.94^{* *} \\
(0.00)\end{array}$ & $\begin{array}{l}-6.65^{* *} \\
(0.00)\end{array}$ & $\begin{array}{l}-0.13 \\
(0.55) \\
\end{array}$ \\
\hline
\end{tabular}

We now turn our attention to the analysis of the cointegration properties of the above set of variables. As discussed in the methodology section, inference on the panel cointegrating rank relies on LLL procedure, requiring individual Johansen's trace test statistics and the computation of the $\overline{L R}_{N, T}$ statistic. As is evident in Table 2, at a full sample level, the most common selected rank is $r=2$ (for 11 regions); for six regions the selected 
rank is $r=3$, and for only three regions the rank is $r=1 .{ }^{16}$ The panel test (see the bottom of Table 2) allows us to sequentially reject the hypothesis that the largest rank of the panel is $r=0, r=1$, and $r=2$. Conversely, the null that $r=3$ cannot be rejected. Notice also that the test gives the same answer at a macro-area level.

\subsection{Short-Run and Long-Run Analysis at the National Level}

In this section, we perform an error-correction analysis to reveal the long-run and short-run behavior of the variables of interest for the entire sample. We use the Schwarz information criterion to select the correct lag order. According to this criterion, the shortrun dynamics are quite similar across regions: only one region out of 20 admits a second lag. We therefore estimate the model considering only one lag in the short-run dynamics of the model. With this specification, the performance of the model shows reasonable fit in terms of test statistics for normality and autocorrelation.

Individual coefficients, reported in Table 3, show an evident tendency to decrease as we go further south in the country. We also find it useful to say here that, as expected for an economically integrated area, misalignments in the level of prices, despite being persistent, are of relatively small size; the lowest $\beta_{1 i}$ is (in modulus) 0.70 for Bas in the south, and the highest is 1.08 for TAA. ${ }^{17}$ These values go together with a maximum and a minimum $\beta_{2 i}$ value of, respectively, 1.13 in Lom and 0.86 in Sic and Pug. To check the consistency of our results with existing literature, we have calculated $\varepsilon_{p_{\text {rel }}, y_{\text {rel }}}$, the implied elasticity between relative prices and relative productivities (cf. last column in Table 3). ${ }^{18}$ Both positive and negative coefficients appear reasonable and comparable to those found by Bergin, Glick, and Taylor (2004) and Alberola and Marqués $(1998,2001){ }^{19}$ The analysis in the following section will ascertain whether these values can be reconciled with a homogeneous predominance of BSE or SDM, at least at the macro-area level.

The full sample, mean-group, long-run elasticities are presented in part A of Table 4 (first row). Individual (not reported) and panel exclusion test statistics (Table 4, part A, row $a$ ) provide overwhelming evidence of the significance of all coefficients. ${ }^{20}$ Notice

\footnotetext{
${ }^{16}$ The critical values for rank selection are, sequentially, 39.89, 24.31, 12.53, and 3.84.

${ }^{17} \mathrm{~A}$ comparable magnitude in the spreads of local prices has been found for Spain at a provincial level by Alberola and Marqués (1998).

${ }^{18}$ After algebraic manipulation of the three ECMs, it is easy to obtain the formula $P_{i, t}-P_{n, t}=\beta_{3 i}\left(\beta_{1 i}-1\right) /\left(\beta_{2 i}-1\right)\left(Y_{i, t}-Y_{n, t}\right)$, which converts our results into a relative-price relativeproductivity framework.

${ }^{19}$ Bergin estimates positive elasticities ranging from 0.12 and 0.32 in post-war data for the European cities. Alberola and Marqués find a negative value of -0.16 in a sample of Spanish provinces.

${ }^{20}$ Recall that as discussed in the methodology section, tests of this kind are conducted cross section by cross section and then, assuming independence, conveyed into the panel context through the computation of LR statistics that are asymptotically distributed as $\chi^{2}(N \times q)$ with $q$ number of restrictions.
} 
that in all testing procedures, as it is customary in this methodology, we have decided not to consider up to three outliers when the remaining sum of individual LR statistics is below the critical values. All the average elasticities bear a negative sign; this implies a positive long-run relationship between local and national prices, between local and national productivities, and between national price and productivity. The homogeneity analysis (Table 4, part A, row $b$ ) confirms the existence of strong disparities across the country, with panel tests rejecting the null of equality of coefficients across units in all cases but for $\beta_{3 i}$. This is not surprising since we expect a local heterogeneous coupling of regional and national productivity and prices but homogenous links between national price and productivity across regions.

TABLE 2

Estimation of the Cointegrating Rank

\begin{tabular}{lcccc}
\hline Regions & $H_{0}: r=0$ & $H_{0}: r=1$ & $H_{0}: r=2$ & $H_{0}: r=3$ \\
\hline Pie & $66.45^{*}$ & $31.80^{*}$ & $12.64^{*}$ & 0.56 \\
VdA & $74.51^{*}$ & 20.96 & 7.65 & 1.55 \\
Lom & $48.09^{*}$ & 21.15 & 9.64 & 2.76 \\
TAA & $85.19^{*}$ & $28.15^{*}$ & 9.08 & 0.30 \\
Ven & $65.97^{*}$ & 22.67 & 5.24 & 0.81 \\
FVG & $70.80^{*}$ & $34.45^{*}$ & $16.15^{*}$ & 3.05 \\
Lig & $61.87^{*}$ & $26.76^{*}$ & 7.80 & 1.02 \\
EmR & $64.59^{*}$ & $30.39^{*}$ & $12.70^{*}$ & 1.62 \\
Tos & $87.39^{*}$ & $42.71^{*}$ & $14.41^{*}$ & 2.83 \\
Umb & $61.48^{*}$ & $33.66^{*}$ & $15.91^{*}$ & 2.20 \\
Mar & $65.37^{*}$ & $30.40^{*}$ & 10.29 & 0.16 \\
Laz & $64.24^{*}$ & $32.66^{*}$ & 12.09 & 1.41 \\
Abr & $46.71^{*}$ & $26.44^{*}$ & 10.96 & 2.66 \\
Mol & $67.70^{*}$ & $27.39^{*}$ & 10.42 & 0.19 \\
Cam & $62.59^{*}$ & $29.34^{*}$ & 10.81 & 3.76 \\
Pug & $60.52^{*}$ & $33.39^{*}$ & 11.85 & $4.66^{*}$ \\
Bas & $72.36^{*}$ & $35.48^{*}$ & $13.25^{*}$ & 1.12 \\
Cal & $76.99^{*}$ & $29.29^{*}$ & 8.81 & 0.71 \\
Sic & $64.42^{*}$ & $28.38^{*}$ & 6.02 & 0.10 \\
Sar & $42.91^{*}$ & $25.05^{*}$ & 9.60 & 0.92 \\
\hline Panel tests (Full Sample) & $25.12^{*}$ & $13.10^{*}$ & $6.45^{*}$ & 1.59 \\
Panel tests (North) & $16.58^{*}$ & $8.87^{*}$ & $3.50^{*}$ & 0.61 \\
Panel tests (Center-South) & $12.40^{*}$ & $8.18^{*}$ & $4.57^{*}$ & 1.08 \\
\hline Starred values denote rejection of the null at a 5\% critical value. & & \\
\hline
\end{tabular}


The Review of Regional Studies, Vol. 36, No. 3, 2006, pp. 400-426

TABLE 3

The Cointegrating Space

\begin{tabular}{lcccc}
\hline Regions & $\beta_{1}$ & $\beta_{2}$ & $\beta_{3}$ & $\varepsilon_{p_{\text {rel }}, y_{\text {rel }}}$ \\
\hline Pie & -1.04 & -1.07 & -0.21 & 0.21 \\
VdA & -0.72 & -1.07 & -0.24 & -0.96 \\
Lom & -0.95 & -1.13 & -0.15 & -0.07 \\
TAA & -1.08 & -1.07 & -0.20 & 0.22 \\
Ven & -1.03 & -1.06 & -0.18 & 0.09 \\
FVG & -1.00 & -1.07 & -0.19 & -0.01 \\
Lig & -1.02 & -0.98 & -0.23 & -0.24 \\
Emr & -1.02 & -1.12 & -0.20 & 0.31 \\
Tos & -1.02 & -1.06 & -0.29 & 0.10 \\
Umb & -0.98 & -0.99 & -0.18 & 0.29 \\
Mar & -0.99 & -1.04 & -0.24 & -0.05 \\
Laz & -1.03 & -1.02 & -0.19 & 0.24 \\
Abr & -0.91 & -0.92 & -0.31 & 0.26 \\
Mol & -0.73 & -0.92 & -0.12 & 0.40 \\
Cam & -0.97 & -0.79 & -0.21 & 0.03 \\
Pug & -1.01 & -0.86 & -0.15 & -0.02 \\
Bas & -0.70 & -1.10 & -0.23 & -0.73 \\
Cal & -0.83 & -0.90 & -0.23 & 0.40 \\
Sic & -0.82 & -0.86 & -0.19 & 0.25 \\
Sar & -1.01 & -0.92 & -0.28 & -0.03 \\
\hline Means & -0.95 & -1.00 & -0.21 & $0.13{ }^{*}$ \\
\hline *Calculation & excludes the extreme values of VdA and Bas. \\
\hline
\end{tabular}

We proceed now to test for PPP and for stationary relative productivities. As already discussed, these hypotheses can be evaluated by respectively testing $H_{0}: \beta_{1 i}=-1$ and $H_{0}: \beta_{2 i}=-1$ against alternative hypotheses. The results, reported in Table 4 , part A, rows $c$ ) and $d$ ), lead to a general rejection of the nulls. Particularly for the case of relative productivity, this does not come as a surprise, given the well-known dualistic structure of the Italian economy.

The (average) short-run parameters $\Gamma$ of the VECM are reported in Table 4, part B, together with relative $p$-values in parentheses. As it is evident from the Table, most of the lagged first difference terms are not significant. This denotes that average cross relationships among variables are generally weak in the full sample. At the same time, all variables other than $Y_{n, t}$ present a statistically significant autocorrelation coefficient.

More than to the $\Gamma$ coefficients, generally capturing inertial factors, we are interested in the statistical significance and size of the coefficients of adjustment ( $\alpha$-coefficients). Note that not all the coefficients are statistically significant; therefore, some of the variables will not be adjusting to the parameters of all the ECMs. In particular, panel tests do not reject the null that none of the ECMs enter the short-run equation for $Y_{n, t}$, at least at a 


\section{TABLE 4}

Results of Estimation: The Full Sample (A): Properties of the Cointegrating Space

Mean Group $\bar{\beta}$

a) LR-stat $\left(H_{0}: \beta_{i j}=0\right)$

b) LR-stat $\left(H_{0}: \beta_{i j}=\bar{\beta}_{j}\right)$

c) LR-stat $\left(H_{0}: \beta_{1 i}=-1\right)$

d) LR-stat $\left(H_{0}: \beta_{2 i}=-1\right)$

\begin{tabular}{ccc} 
ECM1 & ECM2 & ECM3 \\
\hline-0.95 & -0.99 & -0.21 \\
$182.80^{* *}$ & $224.33^{* *}$ & $147.64^{* *}$ \\
$(0.00)$ & $(0.00)$ & $(0.00)$ \\
$78.90^{* *}$ & $75.17^{* *}$ & 11.61 \\
$(0.00)$ & $(0.00)$ & $(0.92)$ \\
$84.61^{* *}$ & - & - \\
$(0.00)$ & - & \\
- & $-110.34^{* *}$ & - \\
& $(0.00)$ &
\end{tabular}

(B): Parameters of the VECM

\begin{tabular}{lcccc}
\multicolumn{5}{c}{ (B): Parameters of the VECM } \\
\hline \multirow{4}{*}{$\Delta P_{i, t-1}$} & $\Delta P_{i, t}$ & $\Delta P_{n, t}$ & $\Delta Y_{n, t}$ & $\Delta Y_{i, t}$ \\
\cline { 2 - 5 } & $0.42^{*}$ & $0.22^{* *}$ & -0.11 & 0.26 \\
$\Delta P_{n, t-1}$ & $(0.03)$ & $(0.00)$ & $(0.23)$ & $(0.12)^{a}$ \\
& $-0.04^{*}$ & $-0.18^{* *}$ & 0.27 & -0.45 \\
$\Delta Y_{n, t-1}$ & $(0.04)$ & $(0.00)$ & $(0.17)^{c}$ & $(0.31)$ \\
& 0.05 & 0.07 & -0.06 & $0.24^{*}$ \\
$\Delta Y_{i, t-1}$ & $(0.13)$ & $(0.43)$ & $(0.07)$ & $(0.03)$ \\
& 0.05 & 0.03 & 0.04 & $-0.13^{*}$ \\
$E C M 1_{t-1}$ & $(0.29)^{c}$ & $(0.53)$ & $(0.36)$ & $(0.05)$ \\
& $-0.30^{* *}$ & $0.19^{* *}$ & 0.26 & -0.24 \\
$E C M 2_{t-1}$ & $(0.00)$ & $(0.00)$ & $(0.18)^{b}$ & $(0.14)^{b}$ \\
& $0.26^{* *}$ & $0.25^{*}$ & -0.28 & $0.35^{*}$ \\
$E C M 3_{t-1}$ & $(0.01)$ & $(0.04)$ & $(0.21)$ & $(0.02)$ \\
& $-0.05^{*}$ & $0.05^{* *}$ & 0.14 & -0.02 \\
& $(0.05)$ & $(0.00)$ & $(0.13)$ & $(0.32)^{a}$ \\
\hline
\end{tabular}

(C): Homogeneity of $\alpha$ and Half-Lives

Homogeneity

\begin{tabular}{|c|c|c|c|}
\hline LR-stat $\left(H_{0}: \alpha_{i 1}=\bar{\alpha}_{i 1}\right)$ & $\begin{array}{c}128.16^{* *} \\
(0.00)\end{array}$ & $\begin{array}{c}114.17^{* *} \\
(0.00)\end{array}$ & - \\
\hline LR-stat $\left(H_{0}: \alpha_{i 2}=\bar{\alpha}_{i 2}\right)$ & $\begin{array}{c}138.24^{* *} \\
(0.00)\end{array}$ & $\begin{array}{l}54.17^{* *} \\
(0.00)\end{array}$ & $\begin{array}{c}-56.98^{* *} \\
(0.00)\end{array}$ \\
\hline LR-stat $\left(H_{0}: \alpha_{i 3}=\bar{\alpha}_{i 3}\right)$ & $\begin{array}{r}18.57^{*} \\
(0.55) \\
\end{array}$ & $\begin{array}{l}16.56 \\
(0.68) \\
\end{array}$ & \\
\hline \multicolumn{4}{|l|}{ Implied half-lives } \\
\hline$\alpha_{\mathrm{i} 1}$ & 1.94 & 3.29 & - \\
\hline$\alpha_{\mathrm{i} 2}$ & 2.30 & 2.41 & -1.61 \\
\hline$\alpha_{\mathrm{i} 3}$ & 12.25 & 11.20 & 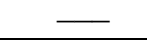 \\
\hline
\end{tabular}


5 percent critical value. This, together with the fact that aggregate and local prices seem to adjust to disequilibria arising from all cointegrating vectors and that regional productivity also adjusts to disequilibrium gaps arising from ECM2, means that aggregate productivity can be taken as the weakly exogenous variable of the system in this sample. In other words, it can be said that aggregate productivity has the role of driving the system in the long run. We find it worth pointing out that our long-run causality scheme is in perfect accordance with the causal ordering implied by BSE and, more in general, with classical theories that attribute a determinant role to real variables in ultimately determining income levels. As to the implied adjustment mechanism of local productivity levels, our empirical evidence is consistent with the existence of some form of positive externalities arising from aggregate productivity shocks. ${ }^{21}$

We now present the estimation of the half-lives based on the estimated alpha coefficients. As is evident from the last rows of Table 4, it takes a long period for national and local prices to dissipate the disequilibrium gap arising from ECM3. It also takes a long time for the aggregate price level to dissipate the disequilibrium arising from ECM1. For the remaining cases, equilibrium gaps are closed after a very short time.

Finally, we turn our attention to the issue of homogeneity of the significant $\alpha$ s. $^{22}$ The panel LR tests (reported in part C of Table 4), conducted under the null that individual regional coefficients in each equation are the same across regions, give evidence of a general lack of homogeneity. We do not reject the null hypothesis only for the third ECM in the short-run equations for $P_{i, t}$ and $P_{n, t}$. This implies that disequilibrium gaps in the long-run relationship between national price and productivity have an uniform impact on regional and aggregate price levels. Disequilibrium gaps arising from other ECMs have, conversely, heterogeneous impacts on our sets of variables.

\subsection{Results at the Macro-Area Level}

The high level of heterogeneity found in the full sample of regions is not fully consistent with our PMG econometric methodology. In the search for a more convenient balance between consistency and efficiency of our estimates, we cluster Northern and Central-Southern regions into two, supposedly more homogeneous, sub-samples (named North and Center-South henceforth). Thus, disaggregating the data set is aimed, on the one hand, to recover more reliable pooled results and, on the other, to investigate whether geographical regularities can be found in the dominance of the BSE or SDM across these macro-areas. It is worth pointing out here that we have decided in all testing procedures,

\footnotetext{
${ }^{21}$ There is much literature developing implications of state-level investments and increased productivity on regions and local firms. Effects of this kind may arise from an increased role for public capital and investments in education, health, and government sectors. Cf., inter alia, Morrison and Schwartz (1996).

${ }^{22}$ For the sake of a simple representation, we have decided to present and discuss homogeneity and half-lives of the coefficients only in cases where the alpha is at least a 5 percent level of significance.
} 
at this stage of analysis, not to consider the largest outlier when the remaining sum of individual LR statistics is below the critical values.

\subsubsection{Long-Run Analysis and Hypothesis Testing}

Tables 5 and 6 report long-run and short-run coefficients, hypothesis testing results, and homogeneity analysis at the macro-area level. The general picture seems now to suggest a much higher degree of homogeneity, both for the $\beta \mathrm{s}$ (cf. row $b$ part $\mathrm{A}$ in all Tables) and $\alpha$ s (cf. part $\mathrm{C}$ in all Tables). Moreover, as it happened for the full-sample case, the $[1,-1]$ form of the first two cointegrating vectors is rejected across all macroareas (cf. rows $c$ and $d$ part $\mathrm{A}$, in all Tables). ${ }^{23}$ However, while homogeneity is the rule within macro-areas, significant differences seem to emerge across the two sub-samples.

We start by discussing the results obtained for North. Table 5, part A, first row, reports the mean-group values of the long-run elasticities generated by the eight Northern regions. Two main findings are worth noting. First, $\bar{\beta}_{1}$ and $\bar{\beta}_{2}$, being equal in modulus to 1.03 and 1.07 , denote, on average, increasing relative prices and productivities. ${ }^{24}$ This does not come as a surprise, at least for $\bar{\beta}_{2}$. The Northern regions belong to the richest part of the country and, as also testified to by a great deal of literature on the issue, ${ }^{25}$ have experimented with an increasing productivity gap with respect to the national average in the last decades. Furthermore, according to our results, it seems that these regions have also had more dynamic price behavior with respect to the national average. This implies a positive correlation between relative prices and relative productivities for this macro-area and therefore the dominance, according to the criterion stated in sub-section 2.1, of a macroeconomic context in line with the BSE. Second, as for the full-sample, this macroarea sees local and national prices adjusting to the parameters of all cointegrating vectors. Interestingly, the adjustment mechanism of the real variables is now qualitatively different than that found at the aggregate level. In detail, it seems that aggregate productivity loses the status of the weak-exogenous variable with respect to the full system and adjusts with respect to disequilibrium gaps arising from ECM2. This implies that the common trend driving the system does not originate only from aggregate output shocks, as found for the full sample of regions. It is also worth observing here that according to the estimated adjustment coefficients, nominal variables require a long time to restore the equilibrium resulting from ECM3. Conversely, half of the disequilibrium gaps arising from the other two ECMs are closed in less than 5 periods.

\footnotetext{
${ }^{23}$ It is confirmed that on average, price misalignments, although persistent, are of relatively small size, especially in North.

${ }^{24}$ The mean-group values of both elasticities have been calculated not taking into account the abnormal values of Vda, a small and relatively unpopulated region.

${ }^{25} \mathrm{Cf}$., inter alia, Costa and Iezzi (2004).
} 
TABLE 5

Results of Estimation: North Sub-Sample (A): Properties of the Cointegrating Space

Mean Group $\bar{\beta}_{j}$

a) $\mathrm{LR}-\operatorname{stat}\left(H_{0}: \beta_{i j}=0\right)$

b) $\mathrm{LR}-\operatorname{stat}\left(H_{0}: \beta_{i j}=\bar{\beta}_{j}\right)$

c) LR-stat $\left(H_{0}: \beta_{1 i}=-1\right)$

d) LR-stat $\left(H_{0}: \beta_{2 i}=-1\right)$

\begin{tabular}{lll} 
ECM1 & ECM2 & ECM3 \\
\hline-1.03 & -1.07 & -0.21
\end{tabular}

$63.81^{* *} \quad 131.26^{* *} \quad 95.05^{* *}$

$\begin{array}{lll}(0.00) & (0.00) \quad(0.00)\end{array}$

$\begin{array}{lll}14.48 & 12.06 & 3.51\end{array}$

$(0.07)^{a} \quad(0.15)^{a} \quad(0.90)$

$23.45^{* *}$

$(0.00)$

$38.45^{* *}$

$(0.00)$

(B): Parameters of the VECM

\begin{tabular}{cccc}
$\Delta P_{i, t}$ & $\Delta P_{n, t}$ & $\Delta Y_{n, t}$ & $\Delta Y_{i, t}$ \\
\hline $0.44^{*}$ & $0.23^{* *}$ & -0.24 & 0.23 \\
$(0.03)$ & $(0.00)$ & $(0.14)$ & $(0.43)$ \\
$-0.02^{*}$ & $-0.16^{* *}$ & 0.19 & -0.38 \\
$(0.02)$ & $(0.00)$ & $(0.11)^{a}$ & $(0.59)$ \\
0.02 & 0.02 & -0.12 & $0.14^{*}$ \\
$(0.07)$ & $(0.09)$ & $(0.83)$ & $(0.05)$ \\
0.07 & 0.06 & 0.09 & -0.19 \\
$(0.04)$ & $(0.76)$ & $(0.45)$ & $(0.07)$ \\
$-0.42^{* *}$ & $0.49^{* *}$ & 0.45 & -0.23 \\
$(0.00)$ & $(0.00)$ & $(0.11)^{a}$ & $(0.87)$ \\
$0.28^{* *}$ & $0.39^{* *}$ & $-0.15^{*}$ & $0.46^{*}$ \\
$(0.00)$ & $(0.00)$ & $(0.02)$ & $(0.03)$ \\
$-0.04^{*}$ & $0.04^{* *}$ & 0.16 & 0.07 \\
$(0.01)$ & $(0.00)$ & $(0.18)^{a}$ & $(0.17)$ \\
\hline
\end{tabular}

(C): Homogeneity of $\alpha$ and Half-Lives

Homogeneity

LR-stat $\left(H_{0}: \alpha_{i 1}=\bar{\alpha}_{i 1}\right) \quad 13.82$

\begin{tabular}{lcccc} 
LR-stat $\left(H_{0}: \alpha_{i 2}=\bar{\alpha}_{i 2}\right)$ & $18.84^{*}$ & 7.39 & 14.38 & 11.86 \\
& $(0.02)$ & $(0.48)$ & $(0.07)^{a}$ & $(0.16)^{a}$ \\
LR-stat $\left(H_{0}: \alpha_{i 3}=\bar{\alpha}_{i 3}\right)$ & 8.57 & 4.17 & - & - \\
\hline
\end{tabular}

Implied half-lives

\begin{tabular}{|c|c|c|c|c|}
\hline$\alpha_{i 1}$ & 1.27 & 1.03 & - & 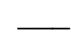 \\
\hline$\alpha_{i 2}$ & 2.11 & 1.40 & 4.27 & 1.12 \\
\hline$\alpha_{i 3}$ & 16.98 & 15.05 & - & 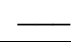 \\
\hline
\end{tabular}


TABLE 6

Results of Estimation: Center-South Sub-Sample (A): Properties of the Cointegrating Space

Mean Group $\bar{\beta}_{j}$

\begin{tabular}{ccc} 
ECM1 & ECM2 & ECM3 \\
\hline-0.92 & -0.93 & -0.21
\end{tabular}

a) LR-stat $\left(H_{0}: \beta_{i j}=0\right)$

$118.99^{* *} \quad 92.97^{* *} \quad 52.59^{* *}$

b) LR-stat $\left(H_{0}: \beta_{i j}=\bar{\beta}_{j}\right)$

$\begin{array}{lll}(0.00) & (0.00) \quad(0.00)\end{array}$

c) LR-stat $\left(H_{0}: \beta_{1 i}=-1\right)$

19.90

17.26

6.17

d) LR-stat $\left(H_{0}: \beta_{2 i}=-1\right)$

$(0.07)$

$(0.14)^{a}$

$(0.91)$

$1.16^{* *}$

$(0.00)$

\begin{tabular}{|c|c|c|c|c|}
\hline & - & $\begin{array}{l}71.89 \\
(0.00) \\
\end{array}$ & \multirow[t]{2}{*}{$\square$} \\
\hline \multicolumn{4}{|c|}{ (B): Parameters of the VECM } & \\
\hline & $\Delta P_{i, t}$ & $\Delta P_{n, t}$ & $\Delta Y_{n, t}$ & $\Delta Y_{i, t}$ \\
\hline$\Delta P_{i, t-1}$ & $\begin{array}{c}0.39^{*} \\
(0.02)\end{array}$ & $\begin{array}{l}0.21^{* *} \\
(0.00)\end{array}$ & $\begin{array}{c}0.08 \\
(0.75)\end{array}$ & $\begin{array}{c}0.25 \\
(0.42)\end{array}$ \\
\hline$\Delta P_{n, t-1}$ & $\begin{array}{c}-0.07^{*} \\
(0.05)\end{array}$ & $\begin{array}{c}-0.22^{* *} \\
(0.00)\end{array}$ & $\begin{array}{c}0.43 \\
(0.07)^{a}\end{array}$ & $\begin{array}{c}-0.47 \\
(0.08)\end{array}$ \\
\hline$\Delta Y_{n, t-1}$ & $\begin{array}{c}0.10 \\
(0.16)\end{array}$ & $\begin{array}{c}0.14 \\
(0.74)\end{array}$ & $\begin{array}{c}-0.01 \\
(0.91)\end{array}$ & $\begin{array}{c}0.12^{*} \\
(0.02)\end{array}$ \\
\hline$\Delta Y_{i, t-1}$ & $\begin{array}{c}0.03 \\
(0.52)\end{array}$ & $\begin{array}{c}-0.02 \\
(0.39)\end{array}$ & $\begin{array}{c}0.01 \\
(0.69)\end{array}$ & $\begin{array}{l}-0.06^{* *} \\
(0.00)\end{array}$ \\
\hline$E C M 1_{t-1}$ & $\begin{array}{l}-0.34^{* *} \\
(0.00)\end{array}$ & $\begin{array}{c}-0.10 \\
(0.61)\end{array}$ & $\begin{array}{c}0.04 \\
(0.86)\end{array}$ & $\begin{array}{l}-0.27 \\
(0.08)^{a}\end{array}$ \\
\hline$E C M 2_{t-1}$ & $\begin{array}{c}0.22^{*} \\
(0.04)\end{array}$ & $\begin{array}{l}-0.08 \\
(0.17)^{a}\end{array}$ & $\begin{array}{c}-0.02 \\
(0.91)\end{array}$ & $\begin{array}{c}0.19^{*} \\
(0.02)\end{array}$ \\
\hline$E C M 3_{t-1}$ & $\begin{array}{l}-0.05 \\
(0.17)^{a} \\
\end{array}$ & $\begin{array}{l}0.05^{* *} \\
(0.00)\end{array}$ & $\begin{array}{c}0.13 \\
(0.24) \\
\end{array}$ & $\begin{array}{c}-0.09 \\
(0.43)\end{array}$ \\
\hline
\end{tabular}

(C): Homogeneity of $\alpha$ and Half-Lives

Homogeneity

LR-stat

$\left(H_{0}: \alpha_{i 1}=\bar{\alpha}_{i 1}\right)$

15.71

LR-stat

$(0.20)^{a}$

$\left(H_{0}: \alpha_{i 2}=\bar{\alpha}_{i 2}\right)$

21.79

(0.04)

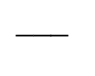

19.35

LR-stat

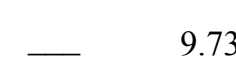

$\left(H_{0}: \alpha_{i 3}=\bar{\alpha}_{i 3}\right)$ (0.64)

Implied half-lives

\begin{tabular}{|c|c|c|c|c|}
\hline$\alpha_{i 1}$ & 4.60 & - & - & - \\
\hline$\alpha_{i 2}$ & 2.79 & - & - & 3.29 \\
\hline$\alpha_{i 3}$ & - & 16.54 & - & - \\
\hline
\end{tabular}


We now turn our attention to Table 6, where the results obtained for Center-South are reported. The estimated mean-group values for $\beta_{1 i}$ and $\beta_{2 i}$, in modulus well below the national averages, imply again a positive correlation between relative price and relative productivity and, therefore, the dominance of the BSE context (cf. first row part A of Table 6). Interestingly, a substantially different picture with respect to the other macroarea emerges for the adjustment coefficients (cf. part B of Table 6). In particular, we find that the role of nominal variables in restoring equilibrium loses weight; in fact, local prices only adjust to disequilibria arising from local productivity and price misalignments. National prices in this macro-area seem to adjust only to disequilibrium gaps arising from aggregate price/productivity misalignments. As far as real variables are concerned, we observe that aggregate productivity regains the status of weak-exogenous variables with respect to the full system. In other words, in this macro-area as in the full sample setting, aggregate shocks to productivity are responsible for driving the system in the long run. Finally, we find that the half-lives based on significant alpha coefficients, as shown in Table 6 Part $\mathrm{C}$, are of comparable magnitude to those found for the Northern regions. The only exception is for the half-live based on $\alpha_{i 1}$, which signals a lengthier adjustment process for local prices in Center-South to nominal misalignments arising from ECM1.

\subsubsection{Contemporaneous Relationships}

In this section we proceed to estimate the contemporaneous relationships for the macro-areas. The matrices are as shown in (13a) and (13b) below report the opposite-insign averages of the estimated coefficients of matrix $A$ for the two sub-samples. ${ }^{26}$

$$
\begin{aligned}
& -A_{\text {NORTH }}=\left[\begin{array}{cccc}
-1 & & & \\
1.13^{*} & -1 & & \\
0.12 & -0.08^{* *} & -1 & \\
-0.09^{*} & 0.04^{* *} & 1.16^{* *} & -1
\end{array}\right] \\
& -A_{\text {CENTER-SOUTH }}=\left[\begin{array}{cccc}
-1 & & & \\
0.83^{* *} & -1 & & \\
-0.08^{*} & 0.13^{*} & -1 & \\
-0.02 & 0.02^{* *} & 0.95^{* *} & -1
\end{array}\right]
\end{aligned}
$$

\footnotetext{
${ }^{26}$ We report the negation of the estimated $A$ matrices for an easier reading of the results.
} 
Starred values denote significant coefficients. In particular, ** and * denote coefficients that are significant at the 1 and 5 percent levels, respectively. For the sake of simplicity, the coefficients arising from the estimation of the B matrix are only reported in the Appendix and not discussed. As explained in the methodology section, short-run coefficients are not restricted to being the same across regions, so we do not have a single pooled estimate for each coefficient. Nevertheless, we can still analyze the average contemporaneous effect by considering the means of the corresponding coefficients across regions.

The results are summarized as follows. The coefficient measuring the simultaneous relationship between aggregate and local productivity (corresponding to coefficient $a_{21}$ ) shows a significant and positive sign for both macro-areas; this means that an aggregate productivity shock is passed to local productivities with the same sign across the country. The elasticity is above unity in the North and below unity in Center-South. As far as the price setting laws are concerned, we observe a great deal of geographical heterogeneity. For Center-South, we find that the estimated parameters indicate that a positive shock in aggregate productivity leads to a fall in the aggregate price index. Conversely, a shock in local productivities leads to a rise in the aggregate price index. The sign scheme is reversed in the North macro-area where, however, the coefficient $a_{31}$, measuring the contemporaneous effect of a shock in $Y_{n, t}$ on $P_{n, t}$, is not significant. Finally, the localprices equation parameters show an homogenous sign scheme across macro-areas. However two characteristics are worth noting here. On the one hand, the contemporaneous effect of an aggregate productivity shock on $P_{i, t}$ is not significant in Center-South; on the other hand, the positive contemporaneous reaction of $P_{i, t}$ to a shock on $P_{n, t}$ is positive everywhere but lower than unity in Center-South.

Given the recursive nature of our identification scheme, the contemporaneous effects analysis is not sufficient to gain a complete picture of the dynamics of the model. From this point of view, the Impulse-Response analysis considered below (Figures $1 a$ and $1 b$ ) can be much more informative. To save space, we only represent the responses of the variables to a 1 percent shock on $Y_{n, t}$, the more exogenous variable according to our identification scheme, for the two sub-samples. ${ }^{27}$ What appears particularly worth discussing is the short-run negative impact of a positive aggregate productivity shock on both $P_{i, t}$ and $P_{n, t}$. After four to eight periods (depending on the macro-area), this effect starts attenuating and, as predicted by our long-run analysis, eventually becomes positive. As also predicted by our long-run analysis, the dynamics of relative prices differ in the macro-areas. In North, we observe an increase of relative productivities and prices following the aggregate shock. Conversely for Center-South, we observe a long-run decrease in relative productivity and price. Notice that especially for North, the movements in relative prices, albeit persistent, are on average quite small.

\footnotetext{
${ }^{27}$ Alternative causal orderings did not produce much different responses in both macro-areas.
} 


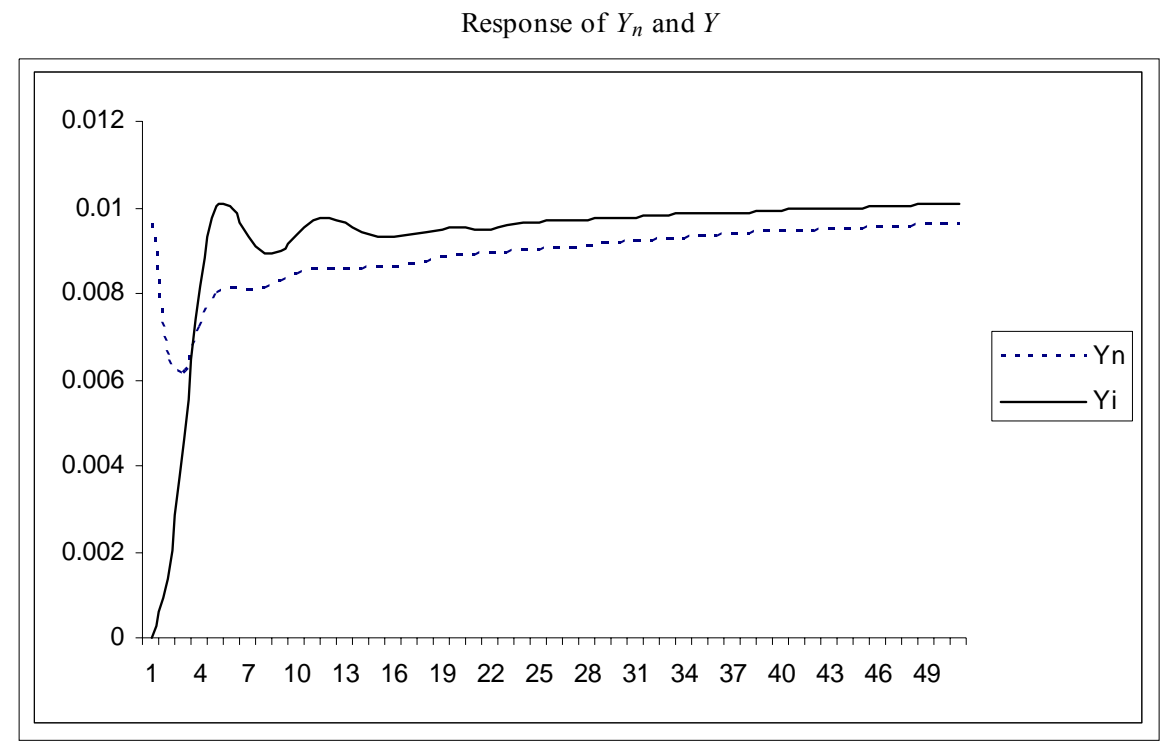

Response of $P_{n}$ and $P_{i}$

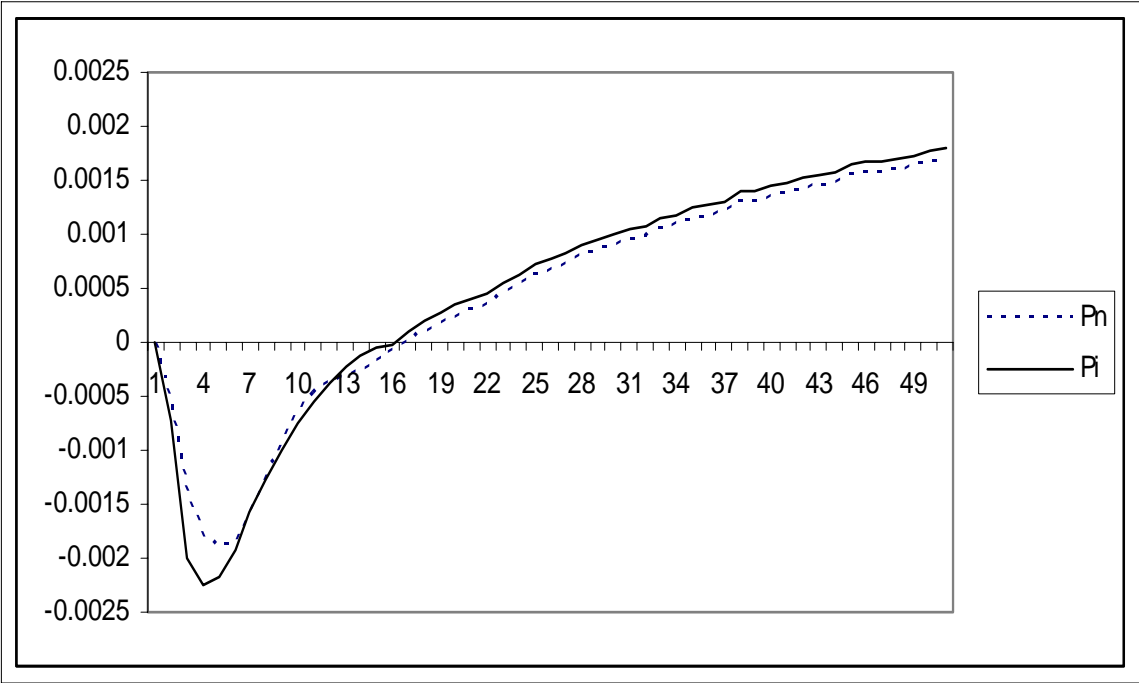

FIGURE 1a. North: Average Responses to a 1 Percent Innovation in $Y_{n}$ 
Response of $Y_{n}$ and $Y_{i}$
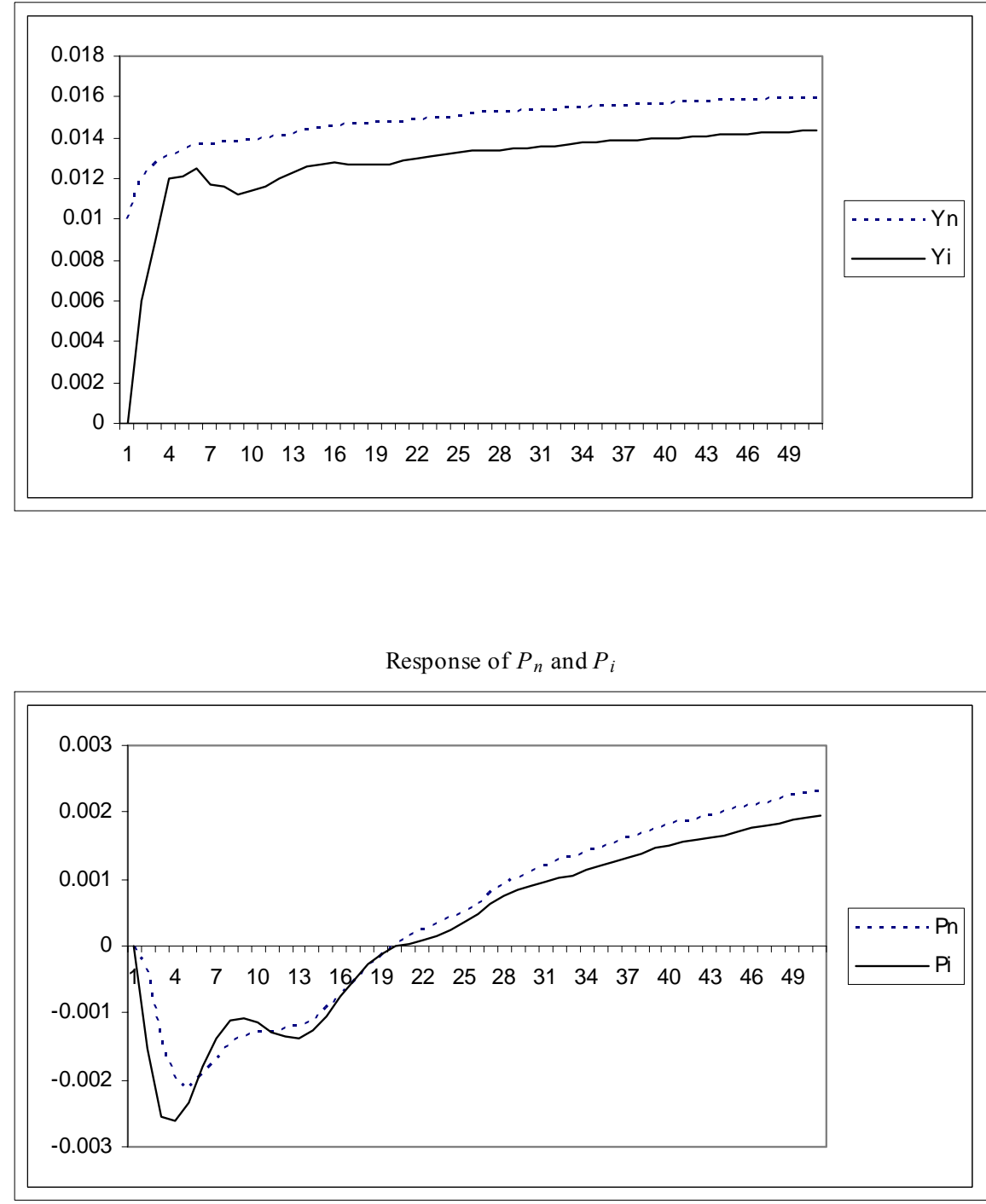

FIGURE 1b. Center-South: Average Responses to a 1 Percent Innovation in $Y_{n}$ 


\section{CONCLUSION}

A commonly quoted explanation proposed in the literature to account for PPP violations in EMU countries is the Balassa-Samuelson effect, which implies a positive correlation between relative prices and relative growth performances. This explanation seems to hold when evaluated at a national level. The results are much more controversial when addressed across regions of the same country where evidence of a more traditional Supply-Demand Mechanism has been found, thus supporting the idea that higher growth in one region has to be associated, in the long run, with a fall in relative prices.

Starting from the idea that shedding light on these topics has interesting implications for the optimal design of policy interventions (in particular for central bank authorities), this paper provides some fresh evidence on the sign of the correlation between relative prices and relative growth performances in a sample of Italian regions. In particular, abstracting from the standard relative-price relative-growth-performance framework, we propose a four-variate Structural VECM to investigate long-run and contemporaneous relationships between the level of regional and national prices and the level of regional and national productivities. The study is first conducted at an aggregate level. Then, because of lack of the necessary homogeneity across units in the long-run parameters, we split our dataset into two sub-samples clustering Northern regions at one side and Central and Southern regions at the other.

As far as the long-run analysis is concerned, we find a three dimensional cointegrating space at both the national and macro-area levels. The first cointegrating vector represents a stable long-run relationship between local and national prices where testing for persistent price misalignments, i.e., PPP violation, is just a matter of restricting coefficients. The second represents a stable long-run relationship between local and aggregate productivity where, again, persistent productivity misalignments can be tested by restricting coefficients. Finally, the third cointegrating vector represents a stable long-run relationship between aggregate price and productivity, which allows testing of the conventional wisdom that richer countries or regions have higher price levels than poorer ones.

The results of our testing procedure can be summarized as follows. At a national level we find a great deal of heterogeneity in the size (but not in the sign) of the long-run elasticities and strong evidence of persistent price and productivity misalignments across regions. In accordance with the Balassa-Samuelson Hypothesis, such misalignments are positively correlated in all samples. The adjustment mechanism is rather intricate and changes across the country. First, again consistent with the Balassa-Samuelson Hypothesis, the burden of the adjustment is mainly borne by the price variables in all samples. Second, aggregate productivity seems to be the driving force at the national level. At a more disaggregated macro-area level, however, this result is only confirmed in the Central-Southern regions. In Northern regions, aggregate productivity does not seem to be weakly exogenous with respect to the full system and shows sign of adjusting to disequilibrium gaps arising from ECM2, the long-run equilibrium law between local and 
national productivity. We give an economic interpretation of this behavior in terms of asymmetric technology diffusion. Northern regions have an advantage in terms of technological spillovers, and aggregate productivity reacts in the long-run to innovations introduced in this part of the country. Conversely, the more peripheral regions are only involved with delay to changes in Northern regions. ${ }^{28}$

The retrieval of the structural coefficients is also rich in powerful insights into the functioning of the Italian economy. In particular, we find that a shock to aggregate productivity (the more exogenous variable, according to our identification scheme) contemporaneously affects local productivities with the same sign across all macro-areas. It is also interesting to note that this contemporaneous elasticity decreases from North to Center-South sub-samples. Moreover, as far as the price setting laws are concerned, we observe a great deal of geographical heterogeneity. For Center-South we find that the estimated parameters indicate that a positive shock in aggregate productivity leads to a fall in the aggregate price index. Conversely, a shock in local productivities leads to a rise in the aggregate price index. The sign scheme is reversed in the North macro-area where, however, the coefficient measuring the contemporaneous effect of a shock to aggregate productivity on the aggregate price level is not significant. Finally, the local-prices equation parameters show a homogenous sign scheme across macro-areas.

Given the recursive nature of our identification scheme, the contemporaneous effects analysis is not sufficient to gain a complete picture of the dynamics of the model. From this point of view, the Impulse-Response analysis can be much more informative. What emerges from this analysis is the short-run negative impact of an aggregate productivity shock on both local and national prices (countercyclical price behavior). After four to eight periods (depending on the macro-area), this effect starts attenuating and, as predicted by our long-run analysis, eventually becomes positive. As also predicted by our long-run analysis, the dynamics of relative prices, however, differ in the macro-areas. For North, we observe an increase of relative productivities and prices following the aggregate shock. Conversely, for Center-South, we observe a long-run decrease of relative productivities and prices.

\section{REFERENCES}

Alberola, E. and J.M. Marqués, 1998. "On the Relevance and Nature of Regional Inflation Differentials: The Case of Spain," Banco de España-Servicio de Estudios Documento de Trabajo 9913. , 2001. "On the Evolution of Relatives Prices and its Nature at Regional Level: The Case of Spain," Journal of Regional Science 41(3), 451-474.

Alberola, E. and T. Tyrväinen, 1998. "Is There Scope for Inflation Differentials in EMU? An Empirical Evaluation of the Balassa-Samuelson Model in EMU Countries," Bank of Finland Discussion Paper 15.

\footnotetext{
${ }^{28} \mathrm{Cf}$., inter alia, Costa and Iezzi (2004).
} 
Amisano, G. and C. Giannini, 1997. Topics in Structural VAR Econometrics. SpringerVerlag: Berlin.

Blanco-Gonzàlez, L. and T.M. Fullerton Jr., 2006. "Borderplex Menu Evidence for the Law of One Price," Economics Letters 90(1), 28-33.

Beck, G., K. Hubrich, and M. Marcellino, 2006. "Regional Inflation Dynamics within and across Euro Area Countries and a Comparison with the U.S.," European Central Bank Working Paper 601.

Bergin, P., R. Glick, and A.M. Taylor, 2004. "Productivity, Tradability and the Long-Run Price Puzzle," Working Paper 10569. National Bureau of Economic Research: Cambridge, MA.

Boswijk, H.P., 1995a. "Conditional and Structural Error Correction Models Reply," Journal of Econometrics 69(1), 173-175.

, 1995b. "Efficient Inference on Cointegration Parameters in Structural Error Correction Models," Journal of Econometrics 69(1), 133-158.

Cecchetti, S.G., N.C Mark, and R.J. Sonora, 1998. "Price Level Convergence among United States Cities: Lessons for the European Central Bank," Oesterreichische Nationalbank Working Paper 32.

, 2002. "Price Index Convergence among United States Cities," International Economic Review 43(4), 1081-1099.

Ceglowski, J., 2003. "The Law of One Price: International Evidence for Canada," Canadian Journal of Economics 36(2), 373-400.

Costa, M. and S. Iezzi, 2004. "Technology Spillovers and Regional Convergence Process: A Statistical Analysis of the Italian Case," Statistical Methods and Applications 13(3), 375-389.

Das, S. and K. Bhattacharya, 2005. "Price Convergence across Regions in India," Bonn Econ Discussion Papers 1.

Drine, I. and C. Rault, 2003. "A Re-Examination of the Balassa-Samuelson Hypothesis Using Recent Panel Data Unit-Root and Cointegration Tests: Evidence from MENA Countries," African Development Review 15(2-3), 106-125.

Égert, B., 2002. "Investigating the Balassa-Samuelson Hypothesis in Transition: Do We Understand What We See? A Panel Study," The Economics of Transition 10(2), 273309.

Égert, B., D. Ritzberger-Grünwald, and M.A. Silgoner, 2004. "Inflation Differentials in Europe: Past Experience and Future Prospects," Monetary Policy and the Economy Q1/04, 47-72.

Engel, C. and J. Rogers, 1996. "How Wide is the Border?" American Economic Review 86(5), 1112-1125.

Fan, C.S. and X. Wei, 2006. "The Law of One Price: Evidence from the Transitional Economy of China," Review of Economics and Statistics 88(4), 682-697.

Hadri, K., 2000. "Testing for Stationarity in Heterogeneous Panel Data," Econometrics Journal 3(2), 148-161.

Honohan, P. and P.R. Lane, 2003. "Divergent Inflation Rates in EMU," Economic Policy 18(37), 357-394.

Issing, O., 2001. "The Single Monetary Policy of the European Central Bank: One Size Fits All," International Finance 4(3), 441-462. 
Im, K., H. Pesaran, and Y. Shin, 2003. "Testing for Unit Roots in Heterogeneus Panels," Journal of Econometrics 115(1), 53-74.

Johansen, S., 1988. "Statistical Analysis of Cointegration Vectors," Journal of Economic Dynamics and Control 12(4), 231-254.

, 1991. "Estimation and Hypothesis Testing of Cointegration Vectors in Gaussian Vector Autoregressive Models," Econometrica 59(6), 1551-1580.

, 1995. Likelihood-Based Interferences in Cointegration Vector Autoregressive Models. Oxford University Press: London.

Karlsson, S. and M. Löthgren, 2000. "On the Power and Interpretation of Panel Unit Root Tests," Economics Letters 66(3), 249-255.

Larsson, R., J. Lyhagen, and M. Löthgren, 2001. "Likelihood-Based Cointegration Tests in Heterogenous Panel," Econometrics Journal 4(1), 109-142.

Levin, A., C.F. Lin, and C.J. Chu, 2002. "Unit Root Tests in Panel Data: Asymptotic and Finite-Sample Properties," Journal of Econometrics 108(1), 1-24.

Lommatzsch, K. and S. Tober, 2004. "The Inflation Target of the ECB: Does the Balassa-Samuelson Effect Matter? Likelihood-Based Cointegration Tests in Heterogeneous Panel," EUI Working Paper RSCAS 19.

Mihalijek, D. and M. Klau, 2004. "The Balassa-Samuelson Effect in Central Europe: A Disaggregated Analysis," Comparative Economic Studies 46(1), 63-94.

Morrison, C.J. and A.E. Schwartz, 1996. "State Infrastructure and Productivity Performance," American Economic Review 86(5), 1095-1111.

Nenna, M., 2001. "Price Level Convergence among Italian Cities: Any Role for the Harrod-Balassa-Samuelson Hypothesis?" Faculty of Economics, University of Rome La Sapienza, mimeo.

Ortega, E., 2003. "Persistent Inflation Differentials in Europe," Banco de España Documento de Trabajo 0305.

Obstfeld, M. and K. Rogoff K., 1996. Foundations of International Macroeconomics. MIT Press: Cambridge MA.

Parsley, D. and S. Wei, 1996. "Convergence to the Law of One Price without Trade Barriers or Currencies Fluctuations," Quarterly Journal of Economics 111(4), 1211236.

Pesaran, M.H., Y. Shin, and R.J. Smith, 1999. "Pooled Mean Group Estimation of Dynamic Heterogeneous Panels," Journal of the American Statistical Association 94(446), 621-634.

Urbain, J.P., 1992. "On Weak Exogeneity in Error Correction Models," Oxford Bulletin of Economics and Statistics 54(2), 187-207. 


\section{APPENDIX}

\begin{tabular}{l|ll}
\multicolumn{3}{c}{ Macro-Area Composition } \\
\hline North & \multicolumn{2}{|c}{ Center-South } \\
\hline Piemonte (Pie) & Toscana (Tos) & Campania (Cam) \\
Valle d'Aosta (VdA) & Abruzzo (Abr) & Puglia (Pug) \\
Lombardia (Lom) & Umbria (Umb) & Basilicata (Bas) \\
Trentino Alto Adige (TAA) & Marche (Mar) & Calabria (Cal) \\
Veneto (Ven) & Lazio (Laz) & Sicilia (Sic) \\
Friuli Venezia Giulia (FVG) & Molise (Mol) & Sardegna (Sar) \\
Liguria (Lig) & & \\
Emilia Romagna (EmR) & & \\
\hline
\end{tabular}

Estimated Parameters of the B Matrix

North

$B=\left[\begin{array}{llll}0.0131^{*} & 0 & 0 & 0 \\ 0 & 0.0114^{*} & 0 & 0 \\ 0 & 0 & 0.0083^{*} & 0 \\ 0 & 0 & 0 & 0.0031^{*}\end{array}\right]$

Center-South

$$
B=\left[\begin{array}{llll}
0.0126^{*} & 0 & 0 & 0 \\
0 & 0.0146^{*} & 0 & 0 \\
0 & 0 & 0.0087^{*} & 0 \\
0 & 0 & 0 & 0.0038^{*}
\end{array}\right]
$$

